MARCO ANTONIO BATISTA DE MOURA ZIEBARTH

\title{
Os poderes do juiz no processo civil brasileiro contemporâneo
}

\author{
Dissertação de Mestrado \\ Orientador: Professor Doutor José Carlos Baptista Puoli
}


MARCO ANTONIO BATISTA DE MOURA ZIEBARTH

\section{Os poderes do juiz no processo civil brasileiro contemporâneo}

Dissertação de Mestrado apresentada à Banca Examinadora do Programa de Pós-Graduação em Direito, da Faculdade de Direito da Universidade de São Paulo, como exigência parcial para obtenção do título de Mestre em Direito, na área de concentração Direito Processual, sob orientação do Professor Doutor José Carlos Baptista Puoli. 
Ziebarth, Marco Antonio Batista de Moura

Os poderes do juiz no processo civil brasileiro contemporâneo / Marco Antonio Batista de Moura Ziebarth: orientador José Carlos Baptista Puoli -- São Paulo, 2018.

227 p.

Dissertação (Mestrado - Programa de Pós-Graduação em Direito Processual) Faculdade de Direito, Universidade de São Paulo, 2018).

1. Poderes do juiz. 2. Função. 3. Discricionariedade. 4. Proporcionalidade. 5. Criatividade judicial. I. Puoli, José Carlos Baptista, orientador. II. Título. 
Para meus pais. 


\section{AGRADECIMENTOS}

Ao Professor José Carlos Baptista Puoli, por me abrir as portas da PósGraduação da Faculdade de Direito do Largo de São Francisco e assumir a orientação desta dissertação, transmitindo profundos ensinamentos que contribuíram para a minha formação acadêmica e para a elaboração do presente trabalho.

Aos membros da banca de qualificação, Professores Ricardo de Barros Leonel e Marcelo José Magalhães Bonizzi, cujas sugestões e diretrizes muito contribuíram para a elaboração e desenvolvimento deste estudo.

Aos meus pais, que apesar da distância sempre me deram todo apoio e estiveram ao meu lado nessa trajetória acadêmica e em todos os momentos que precisei.

Ao meu irmão, pelos conselhos e pela disposição de me auxiliar na reta final deste trabalho. 


\section{RESUMO}

ZIEBARTH, Marco Antonio Batista de Moura. Os poderes do juiz no processo civil brasileiro contemporâneo. 2017. 227 p. Dissertação de Mestrado - Faculdade de Direito, Universidade de São Paulo, São Paulo, 2018.

O presente trabalho tem por objetivo investigar os poderes do juiz no contexto contemporâneo em que é exercida a função jurisdicional. Para tanto, traça-se inicialmente um panorama sobre a posição do Poder Judiciário frente aos demais Poderes estatais para então abordar a função jurisdicional, esboçando suas características na atualidade com enfoque para os fatores que promovem o aumento dos poderes do juiz. Dentre esses fatores, destaca-se a opção do legislador de, muitas vezes, utilizar enunciados normativos que contém termos imprecisos, o que exige tarefa hermenêutica mais intensa e diversa daquele modelo proposto inicialmente pelo positivismo. Com base nesse contexto, analisa-se o papel do juiz no processo civil, de modo que se mostram relevantes os debates muitas vezes levantados pelos defensores de uma postura mais ativa desse agente estatal, visão que confronta com os que pregam por um modo de agir mais neutro. Considerando que os textos legais não raras vezes possuem termos imprecisos e concedem, por consequência, maior liberdade ao juiz, aborda-se o tema da discricionariedade judicial e a importância da proporcionalidade como meio de controlar essa abertura outorgada pelo legislador. Com o advento do recente Código de Processo Civil brasileiro, que procura adotar uma ótica mais cooperativista de processo, discute-se a relevância de se falar hoje em sistemas adversarial e inquisitorial para designar o papel do juiz e das partes no processo, haja vista ainda que legislações processuais de outros países, como Portugal e Inglaterra, também procuram dar destaque à colaboração no processo. Dentro de todo esse contexto, são analisados separadamente cada um dos poderes do juiz, adotando-se uma dentre várias classificações possíveis a respeito. $\mathrm{O}$ estudo desses poderes com base no Código de Processo Civil brasileiro permite verificar que o magistrado possui ampla liberdade em diversos aspectos para cumprir os fins inerentes ao exercício de sua função, o que também dá margem a subjetivismos. Diante disso, estabelecer os limites de atuação legítima torna-se essencial para conformar os poderes-deveres, com a finalidade de não permitir que noções subjetivas de "justiça" atentem contra a legalidade.

Palavras-chave: Poderes do juiz. Função. Discricionariedade. Proporcionalidade. Criatividade judicial. 


\begin{abstract}
ZIEBARTH, Marco Antonio Batista de Moura. The powers of the judge in the brazilian contemporary civil procedure law. 2017. 227 p. Master - Faculty of Law, University of São Paulo, São Paulo, 2017.
\end{abstract}

This dissertation aims to explore the powers of the judge in the contemporary representative democratic landscape. First, this work provides an overview about the position of the Judiciary before the other branches of the State. Following this introduction, the paper addresses the jurisdictional function, drafting its features and focusing on the factors that increase the powers of the judge. Among these factors, I particularly discuss the option of the legislator to adopt normative statements and language containing vague and imprecise terms. The embracement of this language requires more intensive and distinct hermeneutical task than the model initially proposed by the Positivism. Based on this background, I analyse the role of the judge in the civil process, pointing out claims made by those who argued for a more active role of the judge vis-a-vis the claims for a more neutral judicial decision-making. Whereas the legal language often has imprecise terms and provide therefore more freedom to the judge, this work approach subjects as judicial discretion and the role of proportionality as tools to control this opening granted by the legislator. As the Brazilian Civil Procedure Code seeks to embrace a cooperative view of process, this paper examines the relevance of the adversarial and inquisitorial systems to deal with the role of judge and parties in the process. In addition to Brazil, other countries, including but not limited to England and Portugal, have been implementing an approach towards collaboration. Furthermore, this dissertation delves into each power of the judge, adopting one among several possible classifications about this topic. The study over these powers allows to verify that the judge has wide freedom concerning various aspects to fulfil the inherent purposes of her/his role, which also gives room to subjectivism. Therefore, the establishment of the limits of the legitimate action is essential to determine the "powers-duties," with the purpose to not allow that subjective notions of "justice" undermine the rule of law.

Keywords: Powers of the judge. Role of the judge. Discretion. Proportionality. Judicial creativity. Judicial Power. Decision-making. Courts. Justice. Rule of law. 


\section{SUMÁRIO}

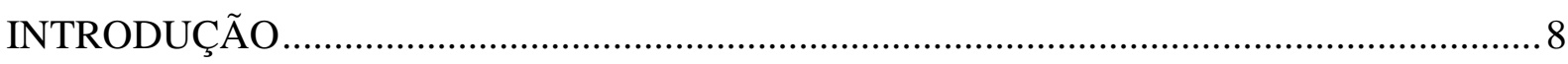

Capítulo 1: O Poder Judiciário e a função jurisdicional no processo civil contemporâneo ..... 14

1.1 Breves considerações acerca da função jurisdicional e sua feição contemporânea ............ 18

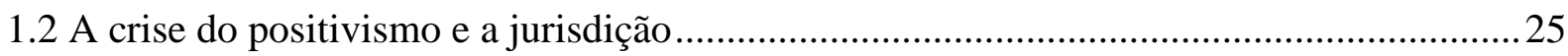

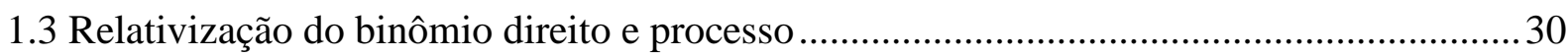

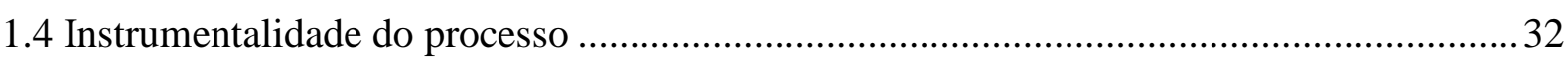

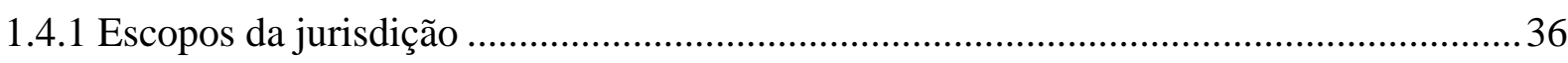

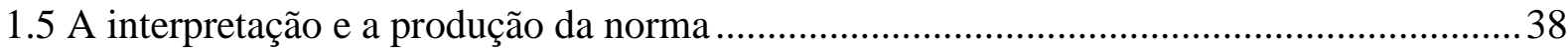

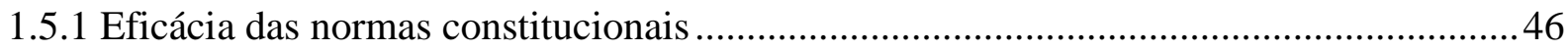

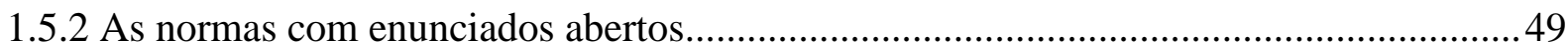

1.6 A jurisdição e as famílias jurídicas ocidentais................................................................. 51

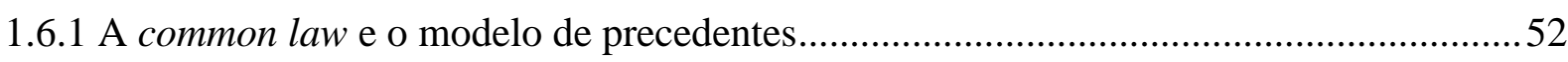

1.6.2 A civil law e a necessidade de estudo do modelo de precedentes da common law .........57

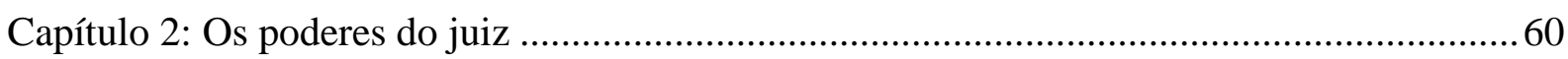

$2.1 \mathrm{O}$ papel do juiz: entre o garantismo e o ativismo judicial ...................................................60

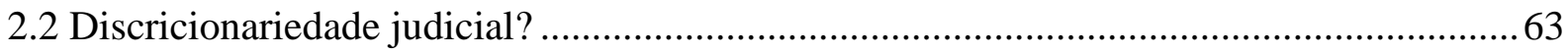

2.3 A atividade do juiz e o princípio da proporcionalidade ................................................ 76

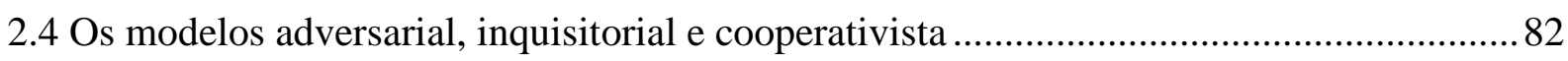

2.4.1 Atenuação do modelo adversarial inglês e o modelo brasileiro pelo CPC/2015 .............84

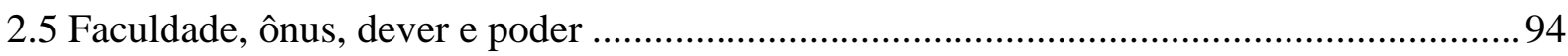

2.5.1 O aumento dos poderes do juiz: fatores e problemas dele decorrentes ........................ 102

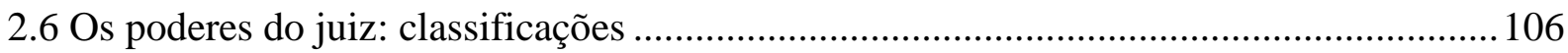

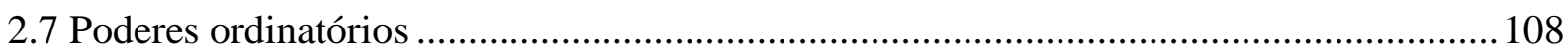

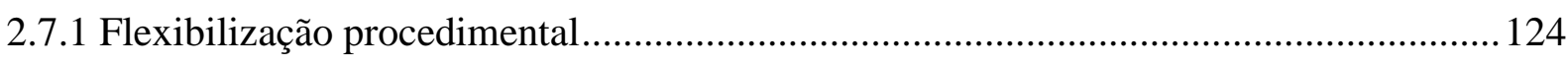

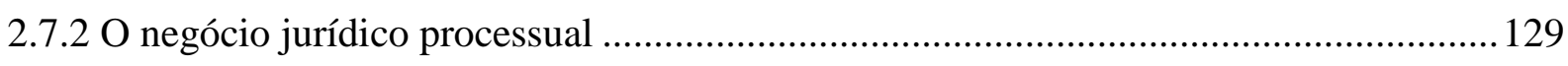

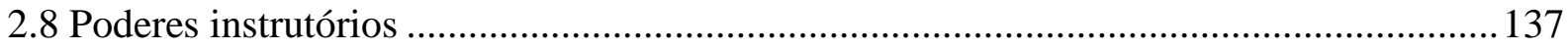

2.8.1 Iniciativas instrutórias pelo juiz e o princípio dispositivo .......................................... 140

2.8.2 Distribuição dinâmica do ônus da prova ........................................................................ 148

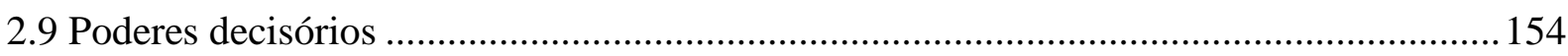

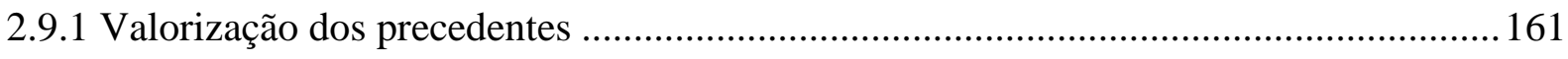

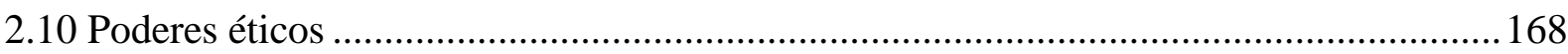




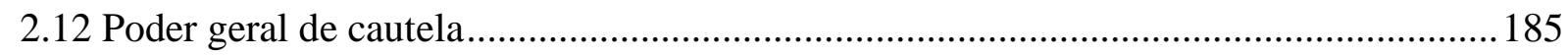

2.12.1 Os requisitos para a concessão das tutelas de urgência .............................................. 188

2.12.1.1 A probabilidade do direito e o perigo de dano ou o risco ao resultado útil do

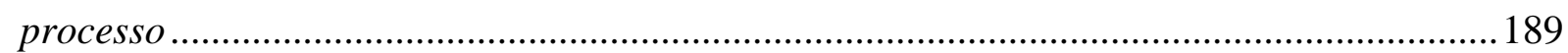

2.12.1.2 Os requisitos da tutela de urgência e o princípio da proporcionalidade.................... 192

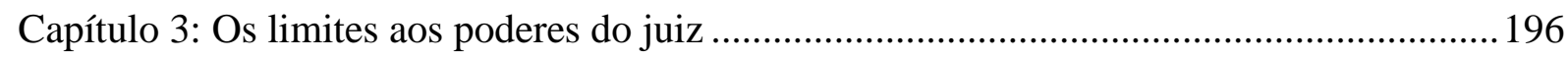

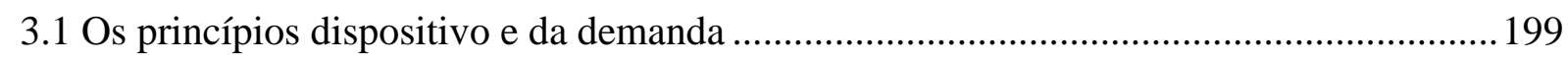

3.2 Separação dos poderes, princípio da legalidade, dever de motivação e valorização dos

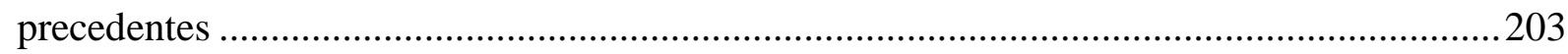

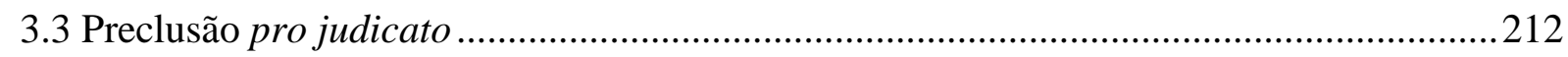

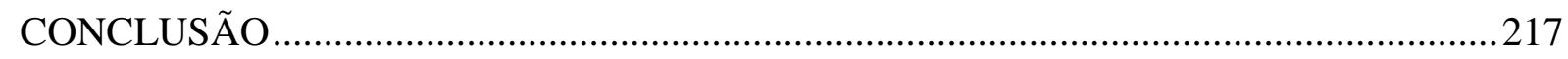

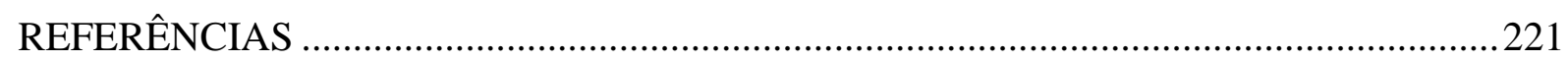





\section{INTRODUÇÃO}

Não é recente a preocupação dos estudiosos das mais variadas áreas do conhecimento acerca da atuação dos juízes e seus poderes. Na Antiguidade Clássica já se realizava esse debate e no texto A República, de Platão, a educação do juiz e a formação de seu caráter são temas tratados por Sócrates no diálogo. Nessa obra, Sócrates já discutia sua preocupação para que o julgador não exercesse seu ofício com base em experiências pessoais que o levem à noção (ou a uma noção) de justiça, devendo adotar distanciamento das relações sociais que podem viciar o verdadeiro conhecimento da natureza da justiça. ${ }^{1}$

Essa breve alusão ao texto clássico de Platão ajuda a apontar algumas questões muito latentes que se encontram até hoje na ciência jurídica, como a noção de justiça e sua aplicação no caso concreto, bem como o papel do juiz na sua efetivação e a postura que deve adotar ao longo do processo para tanto. A formação do magistrado e sua condição de cidadão no exercício da atividade estatal que lhe cabe também constituem matérias de extrema relevância para se pensar o atual estágio da função jurisdicional, principalmente quando se joga a luz sobre os poderes inerentes a essa atividade e seus respectivos limites.

E esse debate faz-se ainda mais premente tendo em vista a posição cada vez mais relevante que o Poder Judiciário tem assumido, o que se deve em boa parte à ampliação dos direitos previstos na Constituição Federal e à construção doutrinária e jurisprudencial que reconhece a eficácia plena e a aplicabilidade imediata à maioria das normas constitucionais. ${ }^{2}$

A própria Constituição elegeu o Supremo Tribunal Federal como o seu guardião (art. 102), e a possibilidade de se proceder ao controle difuso de constitucionalidade permitiu aos juízes que afastem a aplicação de norma contrária ao Texto Magno ao dizer/produzir o direito no caso concreto. Esses traços do sistema jurídico brasileiro revelam a confiança depositada na figura do juiz, confiança essa que, ao mesmo tempo, faz recair sobre os ombros desse agente estatal enormes exigências para a concretização da justiça, além de

\footnotetext{
${ }^{1} \mathrm{O}$ filósofo menciona a necessidade de o juiz ser conhecedor da natureza da justiça, mas explica que esse ${ }^{2}$ José Afonso da Silva explica que a Constituição até apresenta a tendência de deixar a cargo do legislador ordinário a integração e complementação de suas normas, mas, ainda assim, "uma simples análise mostra que a maioria de seus dispositivos acolhe normas de eficácia plena e aplicabilidade direta e imediata." (SILVA, José Afonso da. Aplicabilidade das normas constitucionais. São Paulo: Malheiros, 2002, p. 88-89).
} 
criar, o que parece um paradoxo, receios a respeito da possibilidade de adoção de critérios de índole subjetiva no julgamento de uma causa.

Esse poder concedido ao julgador não é dado sem uma contrapartida. Não apenas a desconfiança pesa sobre essa figura, como também (e antes de mais nada) a exigência para que cumpra um dever na medida em que está investido em uma função. Vale dizer, sobre esse aspecto, um poder pressupõe um dever. O poder dado ao juiz no exercício de sua atividade só é concedido para que possa cumprir os deveres inerentes à sua função. Haja vista então que o dever vem antes do poder é que existem aqueles que preferem a expressão dever-poder do agente estatal em vez de poder-dever. ${ }^{3}$

O presente estudo, dessa feita, terá como objeto de investigação a atividade do julgador no exercício da função jurisdicional. E essa análise se debruçará sobre os fatores que incrementam os poderes do juiz e possibilitam uma atuação criativa; os elementos que limitam esse poder e que constituem uma contrapartida necessária àqueles submetidos à atividade jurisdicional; e a identificação desses poderes no âmbito do processo judicial, de modo a trazer uma possibilidade de classificação.

Nessa perspectiva, o trabalho aqui desenvolvido visa a averiguar os elementos que conduzem ao equilíbrio do poder aqui discutido, de modo que possa este ser efetivo na concretização do direito e que ao mesmo tempo não extrapole a ponto de configurar-se arbitrariedade. Cabe destacar que a ideia de equilíbrio permeia a discussão aqui desenvolvida, tendo como referência os fatores determinantes a uma decisão judicial legítima, que não pende nem para o extremo do excesso do poder, e nem para o outro extremo consistente na atuação tímida e estéril do magistrado, presa pelo rigor do formalismo. ${ }^{4}$

\footnotetext{
3 Acerca dessa noção de dever-poder relacionada à ideia de função, vale trazer os ensinamentos de Celso Antônio Bandeira de Mello: "Existe função quando alguém está investido no dever de satisfazer dadas finalidades em prol do interesse de outrem, necessitando, para tanto, manejar os poderes requeridos para suprilas. Logo, tais poderes são instrumentais ao alcance das sobreditas finalidades. Sem eles, o sujeito investido na função não teria como desincumbir-se do dever posto a seu cargo. Donde, quem os titulariza maneja, na verdade, 'deveres-poderes', no interesse alheio." (BANDEIRA DE MELLO, Celso Antônio. Curso de direito administrativo. São Paulo: Malheiros, 2007, p. 68, grifos no original).

${ }^{4}$ Marcelo José Magalhães Bonizzi, ao discorrer sobre proporcionalidade no processo civil, destaca bem a necessidade de se estabelecer uma linha de equilíbrio na esfera processual, devendo-se verificar até que ponto é legítimo ir na hipótese de a norma não fornecer uma solução satisfatória ao caso concreto. Coerente com essa preocupação, Bonizzi explica que no princípio da proporcionalidade "está apoiada a linha de equilíbrio fundamental do sistema processual, sem o qual não haverá legitimação (formal ou material) das decisões judiciais, a qual somente poderá ocorrer mediante a observância de critérios que proíbam o excesso de poder, o desequilíbrio ou a desnecessidade de certas medidas, nas relações entre o Estado e as pessoas que necessitam de
} 
Para tanto, o primeiro capítulo trata das premissas deste trabalho e discorre acerca da função jurisdicional na atual fase do direito processual civil. Tal abordagem pressupõe avaliar como se apresenta o Poder Judiciário na modelagem contemporânea da separação dos poderes, haja vista que passou a exercer uma postura de maior destaque quando comparada a épocas mais remotas, hoje inclusive com ampla participação política.

Com o intuito de traçar as primeiras diretrizes gerais que serão mais bem discutidas ao longo do estudo, aborda-se de início a atividade jurisdicional diante da crise do positivismo e da constitucionalização do direito.

Esse capítulo inicial ainda traz outros elementos essenciais para compreender, mais especificamente, a fase contemporânea do estudo científico do direito processual civil, como a relação direito material e direito processual, bem como a ótica pautada na instrumentalidade do processo, que passa a exigir que se alcance a ordem jurídica justa e, por consequência, influencia a atividade criativa do juiz. Ao lado disso, outra premissa fundamental e que tem relação direta com a postura do julgador diz respeito à aplicação dos valores constitucionais ao caso concreto, não se limitando a dizer o direito tão somente no plano da legalidade. Ao lado dessa análise, faz-se também fundamental entender a interpretação e criação da norma jurídica pela jurisdição.

Ainda, é relevante traçar um paralelo, mesmo que breve, a respeito das famílias jurídicas ocidentais, quais sejam, common law e civil law, e apontar algumas trocas de experiências entre ambas e que certamente guardam relação com os poderes do juiz, bem como ajudam a compreender melhor a fase contemporânea do processo civil brasileiro.

Após essas breves considerações referentes ao atual estágio da ciência processual, o capítulo segundo será dedicado a situar o papel do juiz no processo civil contemporâneo, abrangendo sua margem de liberdade, muitas vezes outorgada pela própria lei, e seu poder de criação. Então, serão tratadas as correntes garantistas e ativistas com o intuito de levantar seus pontos críticos e encontrar um equilíbrio nos poderes do juiz.

tutela jurisdicional.” (BONIZZI, Marcelo José Magalhães. Proporcionalidade e Processo - a garantia constitucional da proporcionalidade, a legitimação do processo civil e o controle das decisões judiciais. São Paulo: Atlas, 2006, p. 23). 
Além disso, dois temas mostram-se de extrema relevância para analisar o exercício da função jurisdicional na atualidade, quais sejam: princípio da proporcionalidade e discricionariedade judicial. O primeiro tem relação com a própria ideia de equilíbrio que se busca no presente estudo e o segundo debate a liberdade do juiz na aplicação/criação do direito, discutindo se de fato existe uma "discricionariedade" no âmbito judicial. Esses dois temas são fundamentais para entender a margem de liberdade muitas vezes outorgada pela própria legislação ao magistrado.

Então, passa-se a abordar a postura do julgador nos chamados modelos adversarial e inquisitorial, e como se verifica a atenuação desses modelos para a ótica cooperativista, desejada pelo CPC/2015 e que prima pelo diálogo entre as partes e o juiz.

A partir desse ponto, abordadas algumas premissas necessárias, o trabalho passa a dar enfoque específico aos poderes do juiz, tratando inicialmente da noção de poder e sua distinção de outros conceitos como faculdade, ônus, dever. Em seguida, será abordado o aumento dos poderes do juiz, elencando fatores e problemas dele decorrentes.

E então, ainda, o segundo capítulo passará a analisar os poderes em si, adotando-se uma das muitas classificações possíveis, quando também será feito com mais intensidade o estudo com a legislação brasileira, com pontuais considerações atinentes também ao direito estrangeiro. Essa abordagem permeará ainda as questões atinentes ao debate entre ativistas e garantistas, os eventuais traços do almejado modelo cooperativista, a existência ou não de discricionariedade judicial e a pertinência da incidência da proporcionalidade.

Por fim, no terceiro capítulo se debruçará sobre os fatores que limitam os poderes do juiz e correspondem ao seu efetivo controle, de modo a verificar um equilíbrio na atividade jurisdicional. Como todo poder, ao menos em uma sociedade que preza por liberdades fundamentais, encontra fronteiras e passa por controles, essa parte final do trabalho trata de questões essenciais até para o regime democrático, com ponderações pertinentes acerca da necessidade desse agente estatal prestar contas.

Por meio dessas etapas, procura-se, sem a pretensão de trazer conclusões definitivas, contribuir para o debate em torno dos poderes do juiz, traçando elementos que 
trazem equilíbrio à atuação do julgador, eliminando, ou ao menos mitigando, a possibilidade de arbitrariedades e afastando uma postura omissa e não condizente com o processo civil contemporâneo.

Como se pode observar, o tema objeto deste estudo, como tantos outros atinentes à ciência processual, é terreno fértil para intensos debates. O Poder Judiciário, no atual estágio da maioria das democracias ocidentais, conheceu uma ampliação de suas atribuições, passando a resolver questões de âmbito público cujo foro de decisão competia, tradicionalmente, mais ao Executivo e ao Legislativo. Muito tem-se falado nos últimos anos de protagonismo do Judiciário e ativismo judicial com o intuito de descrever essa nova postura no exercício da função jurisdicional.

Não há como não reconhecer que, nesse contexto, o papel do juiz ganha novos contornos. Coerente com a visão publicista do processo, o magistrado passou a ser reconhecido como um agente estatal no desempenho de uma função pública pautada não apenas na mera satisfação das partes envolvidas no litígio, mas principalmente na aplicação da ordem jurídica justa.

Essa postura ativa e participativa do juiz, no entanto, merece resguardos e não pode ser encarada, obviamente, de forma absoluta. Diante do poder que o magistrado passou a deter em razão da ótica pautada na instrumentalidade do processo e da necessidade de muitas vezes definir, no caso concreto, interesses que ultrapassam a esfera de direitos das partes litigantes, intensificou-se o receio de que o poder criativo do magistrado pudesse desembocar em arbitrariedades e subjetivismos.

Nesse sentido, o tema desenvolvido reside também na tentativa de identificação, delimitação e controle dos poderes do juiz no processo civil. A própria amplitude do papel que o Judiciário tem assumido já revela a pertinência do estudo, dado que muitas das decisões proferidas atingem uma coletividade de pessoas, tornando-se imprescindível a compreensão dos institutos envolvidos.

A recente entrada em vigor de um novo código processual intensifica a necessidade desse debate, já que trouxe da experiência estrangeira institutos processuais antes aqui inexistentes. 
Dessa forma, além da análise do ordenamento jurídico nacional e da contextualização do atual estágio do direito processual civil, revisitando institutos clássicos da ciência processual e compreendendo-os à luz da dinâmica contemporânea, é importante também abordar experiências do direito estrangeiro, que também acabam por influenciar o direito pátrio, e verificar ainda que brevemente como se posiciona a figura do juiz em sistemas tradicionalmente distintos do brasileiro.

Assim, o debate acerca dos limites e mecanismos de controle do exercício da função jurisdicional é de extrema relevância para se chegar a uma linha de equilíbrio dos poderes do juiz condizente com o Estado Democrático. 


\section{CONCLUSÃO}

O estudo dos poderes do juiz exige, como se viu, uma análise que parte desde a posição do Judiciário frente aos demais Poderes estatais, passando pela atual caracterização da função jurisdicional, até a abordagem dos dispositivos legais que regulam sua postura no processo civil.

No primeiro capítulo deste trabalho, deu-se uma visão ampla do papel exercido pelo Poder Judiciário na atualidade, que assumiu nas últimas décadas, ao menos nos Estados democráticos, uma posição equivalente comparado com os demais. Dentro do quadro dos Poderes do Estado, verifica-se que esse enquadramento do Judiciário é mais condizente com a ideia de harmonização junto ao Legislativo e ao Executivo.

Não se pode negar também que, no momento atual, em que se observa em diversos países democráticos a ascensão do populismo, seja de orientação política de esquerda ou de direita, as supremas cortes passam a ter papel de relevo na preservação de direitos

fundamentais previstos nas constituições. É assim que, como escreve Hamilton, defende-se a Lei Fundamental da tirania da maioria.

Junto dessa abordagem sobre a posição do Judiciário dentro do quadro político constitucional, também foi analisada a feição contemporânea da função jurisdicional com o intuito de melhor esboçar o contexto em que se inserem os poderes do juiz. Nesse sentido, a chamada "crise do direito" demandou dessa função uma nova gama de atribuições consistente em suprir o déficit da legislatura, que não consegue acompanhar o dinamismo dos acontecimentos sociais para devidamente regulá-los.

Diante disso, a função jurisdicional abre consideravelmente o seu leque de competências, principalmente quando comparada com aquela visão dos positivistas da Revolução Francesa, que enxergavam o juiz como mera boca da lei. O fenômeno da constitucionalização do direito contribuiu consideravelmente para isso, além de permitir que questões cuja solução não se encontre na legislação infraconstitucional sejam buscadas também na Constituição. 
Esse expediente, no entanto, confere alto grau de liberdade ao juiz e abre campo para eventuais subjetivismos, já que se vale da aplicação de princípios com baixa densidade normativa. Outro recurso utilizado para suprir a "crise do direito" consiste na escolha do próprio legislador de inserir no texto legal cláusulas gerais e conceitos jurídicos indeterminados, permitindo ao magistrado proferir a decisão mais justa para o caso concreto dentro dos parâmetros estabelecidos pela lei.

Essa atividade desenvolvida pelo juiz deve levar em conta também as características da função jurisdicional na contemporaneidade, atentando-se aos escopos do processo, seu caráter instrumental e a necessidade de se relativizar o binômio direito material e direito processual. Como visto, o exercício dessa função tornou-se bastante complexo diante dessas inúmeras atribuições, somando-se ao fato de que o Judiciário ganhou maior relevância junto aos demais Poderes estatais e passou a decidir também questões de ordem política, promovendo o controle do Executivo e do Legislativo.

Nessa perspectiva, até em razão de toda a complexidade envolvendo a aplicação do direito, é possível afirmar que o juiz produz a norma jurídica quando profere uma decisão. Há que se fazer a distinção entre texto legal e norma, sendo que esta é o produto da interpretação daquela. Muito se disse ao longo do presente trabalho que o julgador produz a norma jurídica, mas é importante frisar também que qualquer intérprete do texto legal realiza essa operação, apenas é o magistrado o intérprete autêntico. Aliás, diversos conflitos são solucionados sem que sejam levados ao Judiciário, já que cabe às partes interpretar a lei e muitas vezes chegam por si próprias a um consenso.

Também não se quer dizer que, com isso, o juiz possua ampla liberdade, como se criasse o direito sem qualquer baliza. $\mathrm{Na}$ verdade, a própria lei já constitui um grande limitador, de modo que não é permitido ao juiz, a não ser em casos excepcionais de inconstitucionalidade, extrapolar os contornos por ela traçados. Em suma, afirmar que o magistrado produz o direito não corresponde, de maneira alguma, dizer que lhe é possível contrariar o princípio da legalidade.

Nesse contexto, não há como negar que o atual estágio da função jurisdicional consistiu no incremento dos poderes do juiz. A despeito de os argumentos da corrente garantista terem relevância nesse debate, constituindo um contraponto necessário, o que se 
verifica, pelo menos nos ordenamentos brasileiro, inglês e português, é a presença de um juiz ativo na condução do processo.

Essa abertura para que o magistrado assuma uma postura mais ativa decorre da própria lei, que muitas vezes utiliza-se de cláusulas gerais e conceitos jurídicos indeterminados para que o juiz tenha maior liberdade no exercício de sua atividade e possa atingir as finalidades inerentes à função jurisdicional. Diante dessas circunstâncias é que se reconhece aqui a existência de discricionariedade judicial. Conforme desenvolvido no Capítulo 2 deste trabalho, afirmar que há discricionariedade no âmbito judicial depende muito da própria ideia que se tem de "discricionariedade". Como visto, adotou-se definição trazida do Direito Administrativo que aponta que existe discricionariedade na aplicação de conceitos jurídicos indeterminados e cláusulas gerais, ainda que se reconheça o dever de atingir, da melhor forma, uma finalidade expressa em lei.

Em razão desse cenário em que o julgador encontra balizas não muito precisas para cumprir sua tarefa, o princípio da proporcionalidade mostra-se uma ferramenta essencial. Já no início foi dito que a ideia de equilíbrio permeia os temas analisados neste estudo, constituindo um verdadeiro objetivo para que a decisão seja justa. Com o intuito de não deixar margens muito amplas de liberdade ao juiz, uma vez que a própria ideia de “proporcionalidade", por si só, não é precisa, procurou-se elencar seus subprincípios de modo a permitir sua aplicação de forma mais racional, privilegiando a motivação e o controle das decisões.

A esse respeito, verificou-se que o CPC/2015 procura imprimir um modelo cooperativista de processo, com disposições muitas vezes genéricas que exigem a colaboração entre o juiz e as partes. Os sistemas processuais inglês e português também procuram seguir essa toada, mitigando os traços de seus respectivos modelos (adversarial para o primeiro e inquisitorial para o segundo) para uma ótica mais cooperativa.

Dessa nova proposta do CPC/2015 decorrem outros deveres ao magistrado (esclarecimento, consulta, prevenção e auxílio) que, todavia, tornam ainda mais complexo o exercício de sua função. Em alguns dispositivos desse diploma, o "dever" de colaboração do juiz chega a ponto de ter que determinar à parte "o suprimento de pressupostos processuais e o saneamento de outros vícios processuais" (art. 139, inciso IX), ou até mesmo de intimar o 
autor da ação a emendar ou completar a petição inicial quando esta não preencher os requisitos essenciais, "indicando com precisão o que deve ser corrigido ou completado" (art. 321, caput). Embora essas previsões tenham como objetivo um processo mais efetivo, privilegiando-se a decisão de mérito, é difícil imaginar o pleno cumprimento de todas as exigências decorrentes do princípio da colaboração, ainda mais quando se constata a situação dos tribunais brasileiros, abarrotados de processos aguardando decisão.

Quando tratados especificamente os poderes do juiz, foi possível ter uma ideia das dificuldades que podem advir da necessidade de agir sempre de forma colaborativa. É claro que essas disposições legais possuem metas louváveis, mas não é fácil vislumbrar como o magistrado, diante da estrutura interna dos tribunais, possa atendê-las em sua integralidade.

De todo modo, não há dúvidas de que na evolução do processo civil verifica-se o aumento dos poderes do juiz. O CPC/2015 não dispensa o uso de cláusulas gerais e conceitos jurídicos indeterminados ao tratar dos poderes-deveres do magistrado, o que impõe ainda mais a necessidade de controle sobre a atividade por ele desempenhada, de forma a evitar arbitrariedades e excessos. Até em razão disso que se dedicou um capítulo específico para abordar os limites da atuação judicial.

Apesar de ser evidente esse incremento dos poderes do juiz, não parece razoável depositar nesse expediente a meta de melhorar a prestação jurisdicional. Não se observa aqui correlação necessária entre aumento dos poderes e efetividade do processo. Como repisado inúmeras vezes neste trabalho, a ideia de equilíbrio é essencial para a melhor compreensão da ideia de poder, já que, se de um lado não se admite uma atuação tímida e estéril do juiz, de outro devem ser repelidos o excesso de poder e arbitrariedades. É com essa balança que merece ser conduzido este debate, sempre atentando-se também aos mecanismos de controle da atuação estatal. 


\section{REFERÊNCIAS}

ALLAN, Trevor. Constitutional justice: a liberal theory of the rule of law. Oxford: Oxford University Press, 2001.

AMENDOEIRA JR., Sidnei. Poderes do juiz e tutela jurisdicional. São Paulo: Atlas, 2006.

AMPLIAÇÃO dos poderes do juiz no novo CPC e princípio da legalidade. Disponível em: $<$ https://www.conjur.com.br/2016-set-27/paradoxo-corte-ampliacao-poderes-juiz-cpcprincipio-legalidade $\geq$. Acesso em 27.12.2017.

ANDREWS, Neil. $O$ moderno processo civil: formas judiciais e alternativas de resolução de conflitos na Inglaterra. Tradução Teresa Arruda Alvim Wambier. São Paulo: Revista dos Tribunais, 2009.

AROCA, Juan Montero. El proceso civil llamado 'social' como instrumento de 'justicia' autoritaria. In (coord.). Proceso e ideología. Valencia: Tirant lo Blanch, 2006.

ÁVILA, Humberto. Teoria dos princípios, da definição à aplicação dos princípios jurídicos. São Paulo: Malheiros, 2015.

BANDEIRA DE MELlO, Celso Antônio. Curso de direito administrativo. São Paulo: Malheiros, 2007.

Discricionariedade e controle jurisdicional. São Paulo: Malheiros, 2012.

BARBERIS, Mauro. Separazione dei poteri e teoria giusrealista dell'interpretazione. Disponível

em <http://www1.unipa.it/gpino/Barberis,\%20Separazione\%20dei\%20poteri\%20e\%20giusrealis mo.pdf >. Acesso em 11.06.2017.

BARBOSA MOREIRA, José Carlos. Os poderes do juiz na direção e na instrução do processo. In . Temas de direito processual civil - Quarta série. São Paulo: Saraiva, 1989.

O problema da "divisão do trabalho" entre juiz e partes: aspectos terminológicos. In Temas de direito processual civil - Quarta série. São Paulo: Saraiva, 1989.

O processo civil contemporâneo: um enfoque comparativo. In Temas de direito processual - Nona série. São Paulo: Saraiva, 2007.

Regras de experiência e conceitos juridicamente indeterminados. Revista Forense, Rio de Janeiro: Forense, vol. 261, ano 74, p. 15, jan./fev./mar. 1978.

BARROSO, Luís Roberto. Judicialização, ativismo judicial e legitimidade democrática, p. 6. Disponível em: <http://www.cnj.jus.br/eadcnj/mod/resource/view.php?id=47743>. Acesso em 27.12.2017

BEDAQUE, José Roberto dos Santos. Poderes instrutórios do juiz. São Paulo: Revista dos Tribunais, 2013. 
Direito e processo. São Paulo: Malheiros, 2011.

- Tutela provisória: considerações gerais. In O novo Código de Processo Civil: questões controvertidas (vários autores). São Paulo: Atlas, 2015.

BERIZONCE, Roberto Omar. “Acitivismo judicial y participación en la construcción de las políticas públicas”. Revista de Processo, São Paulo: Revista dos Tribunais, p. 45, 2010.

BOBBIO, Norberto. O positivismo jurídico: lições de filosofia do direito. Tradução Márcio Pugliese. São Paulo: Ícone, 2006.

BONAVIDES, Paulo. Curso de direito constitucional. São Paulo: Malheiros, 2006.

BONIZZI, Marcelo José Magalhães. Proporcionalidade e processo - A garantia constitucional da proporcionalidade, a legitimação do processo civil e o controle das decisões judiciais. São Paulo: Atlas, 2006.

CAMPILONGO, Celso Fernandes. Política, sistema jurídico e decisão judicial. São Paulo: Saraiva, 2011.

CAPONI, Remo. Autonomia privata e processo civile: gli accordi processual. Civil Procedure

Review, vol. 1, n. 2, jul./set. 2010. Disponível em: <http://www.civilprocedurereview.com/busca/baixa_arquivo.php?id=19\&embedded=true $>$. Aceso em 27.12.2017.

CAPPELLETTI, Mauro. Judicial review in comparative perspective (tradução livre). California Law Review, vol. 58, n. 5, p. 1018, 1970. Fabris, 1999.

Juizes legisladores? Tradução Carlos Alberto Álvaro de Oliveira. Porto Alegre: Processo, ideologias e sociedade. Porto Alegre: Sergio Antonio Ed., 2008.

CARMONA, Carlos Alberto. O novo código de processo civil e o juiz hiperativo. In $O$ novo código de processo civil (vários autores). São Paulo: Atlas, 2015.

CARNELUTTI, Francesco. Como se faz um processo. Campinas: Minelli, 2002.

Sistema de direito processual civil. Tradução Hiltomar Martins Oliveira. São Paulo: Lemos e Cruz, 2004.

CARVALHO, José Murilo de. Cidadania no Brasil: o longo caminho. Rio de Janeiro: Civilização Brasileira, 2004.

CASTRO, Carlos Roberto Siqueira. O devido processo legal e os princípios da razoabilidade e da proporcionalidade. Rio de Janeiro: Forense, 2006.

CHAYES, Abram. The role of the judge in public law litigation. Harvard Law Review, vol. 89, p. 1282-1283, mai.1976.

CHIOVENDA, Giuseppe. Principii di diritto processuale civile: le azioni. Il processo di cognizione. Napoli: Casa Editrice Dott. Eugenio Jovene, 1965.

CORRÊA, Fábio Peixinho Gomes. Governança judicial. São Paulo: Quartier Latin, 2012. 
COSTA NETO, José Wellington. Protagonismo judicial - proposta de uma teoria geral contemporânea da função jurisdictional. São Paulo: USP / Faculdade de Direito, 2015.

CRUZ E TUCCI, José Rogério. Ampliação dos poderes do juiz no novo CPC e princípio da legalidade. Disponível em: <https://www.conjur.com.br/2016-set-27/paradoxo-corteampliacao-poderes-juiz-cpc-principio-legalidade>. Acesso em 27.12.2017.

Precedente judicial como fonte do direito. São Paulo: Revista dos Tribunais, 2004.

CRUZ E TUCCI, José Rogério; AZEVEDO, Luiz Carlos de. Lições de história do processo civil romano. São Paulo: Revista dos Tribunais, 2001.

CUNHA, Leonardo Carneiro da. Negócios jurídicos processuais no processo civil brasileiro. In Negócios processuais. Antonio do Passo Cabral, Pedro Henrique Nogueira (coords). Salvador: JusPodivm, 2005.

DALLARI, Dalmo de Abreu. Elementos de Teoria Geral do Estado. São Paulo: Saraiva, 2005.

O poder dos juízes. São Paulo: Saraiva, 2007.

DEPARTMENT FOR CONSTITUTIONAL AFFAIRS. Access to Justice - Interim Report to the Lord Chancellor on the civil justice system in England and Wales. Disponível em: <http://webarchive.nationalarchives.gov.uk/+/http://www.dca.gov.uk/civil/interfr.htm>/ <http://webarchive.nationalarchives.gov.uk/+/http:/www.dca.gov.uk/civil/final/contents.htm>. Acessos em 27.12.2017.

DIDIER JR., Freddie. Fundamentos do princípio da cooperação no direito processual civil português. Coimbra: Wolters Kluwer Portugal/Coimbra Editora, 2010.

Princípio do respeito ao autorregramento da vontade no processo civil. In Negócios processuais. Antonio do Passo Cabral, Pedro Henrique Nogueira (coords). Salvador: JusPodivm, 2005.

DINAMARCO, Cândido Rangel. A instrumentalidade do processo. São Paulo: Malheiros, 2009.

Instituições de direito processual civil. São Paulo: Malheiros, 2017. Vol. I. Instituições de direito processual civil. São Paulo: Malheiros, 2017. Vol. II Instituições de direito processual civil. São Paulo: Malheiros, 2017. Vol III. Instituições de direito processual civil. São Paulo: Malheiros, 2005. Vol. IV.

DINAMARCO, Cândido Rangel; LOPES, Bruno Carrilho. Teoria geral do novo processo civil. São Paulo: Malheiros, 2016.

DWORKIN, Ronald. Law's Empire. Cambridge: Harvard University Press, 1995.

. Taking rights seriously. Cambridge: Harvard University Press, 1978.

FERRAZ JÚNIOR, Tércio Sampaio. Apresentação. In LUHMAN, Niklas. Legitimação pelo procedimento. Brasília: Editora Universidade de Brasília, 1980. 
FERREIRA, William Santos. Princípios fundamentais da prova cível. São Paulo: Revista dos Tribunais, 2014.

FISS, Owen M. Two Models of Adjudication. In GOLDWIN, Robert; SCHAMBRA, William. How Does the Constitution Secure Rights? Estados Unidos da América: American Enterprise Institute, 1985.

FRANCISCO, João Eberhardt. O papel do juiz na efetivação dos valores constitucionais do processo. Dissertação de Mestrado. Faculdade de Direito da Universidade de São Paulo, São Paulo, 2014.

GAJARDONI, Fernando da Fonseca. Flexibilização procedimental: um novo enfoque para o estudo do procedimento em matéria processual, de acordo com as recentes reformas do CPC. São Paulo: Atlas, 2008.

O modelo presidencial cooperativista e os poderes e deveres do juiz do Novo CPC. In $O$ novo código de processo civil (vários autores). São Paulo: Atlas, 2015.

GERHARDT, Michael J. The power of precedent. Oxford: Oxford University Press, 2008.

GRAU, Eros Roberto. O direito posto e o direito pressuposto. São Paulo: Malheiros, 2003. Por que tenho medo dos juízes. São Paulo: Malheiros, 2014.

GRINOVER, Ada Pellegrini. O processo em evolução. Rio de Janeiro: Forense Universitária, 1996.

GRINOVER, Ada Pellegrini; WATANABE, Kazuo; MULLENIX, Linda. Os processos coletivos nos países de civil law e common law: uma análise de direito comparado. São Paulo: Revista dos Tribunais, 2011.

HAZARD, Geoffrey; TARUFFO, Michele. American civil procedure: an introduction. New Haven: Yale University Press, 1993.

KOCHEM, Ronaldo. Racionalidade e decisão - a fundamentação das decisões judiciais e a interpretação jurídica. Revista de Processo, São Paulo: Revista dos Tribunais , vol. 244, ano 40, p. 62, jun. 2015.

LEONEL, Ricardo de Barros. Considerações introdutórias sobre o direito processual constitucional. In PUOLI, José Carlos Baptista; BONIZZI, Marcelo José Magalhães; LEONEL, Ricardo de Barros (coords). Direito Processual Constitucional. Brasília: Gazeta Jurídica, 2016.

LIEBMAN, Enrico Tulio. Manuale de Diritto Processuale Civile. Milão: Dott. A. Giuffrè Editore, 1973. Vol. 1.

LUHMAN, Niklas. Legitimação pelo procedimento. Brasília: Editora Universidade de Brasília, 1980.

MADISON, James; HAMILTON, Alexander; JAY, John. O federalista. São Paulo: Abril Cultural, 1979. 
MARINONI, Luiz Guilherme. Aproximação crítica entre as jurisdições de civil law e de common law e a necessidade de respeito aos precedentes no Brasil. Revista Forense, vol. 401, p. 269, jan./fev., 2009.

MARINONI, Luiz Guilherme; ARENHART, Sérgio Cruz; MITIDIERO, Daniel. Novo curso de processo civil: teoria do processo civil. São Paulo: Revista dos Tribunais, 2015. Vol. 1.

; Novo curso de processo civil: tutela dos direitos mediante procedimento comum. São Paulo: Revista dos Tribunais, 2015. Vol. 2.

MEIRELES, Edilton. Medidas sub-rogatórias, coercitivas, mandamentais e indutivas no Código de Processo Civil de 2015. Revista de Processo, São Paulo: Revista dos Tribunais, n. 247, ano 40, p. 239, set./2015.

MENDES, Gilmar Ferreira; COELHO, Inocêncio; BRANCO, Paulo. Curso de direito constitucional. São Paulo: Saraiva, 2009.

MIRANDA, Vicente. Poderes do juiz no processo civil brasileiro. São Paulo: Saraiva, 1992.

MOREIRA, José Carlos Barbosa. Temas de direito processual civil: quinta série. São Paulo: Saraiva, 1989.

NAGAO, Paulo Issamu. O papel do juiz na efetividade do processo civil contemporâneo. São Paulo: Malheiros, 2016.

NERY JR., Nelson. Princípios do processo na Constituição Federal: processo civil, penal e administrativo. São Paulo: Revista dos Tribunais, 2009.

NERY JR., Nelson; NERY, Rosa Maria. Comentários ao código de processo civil. São Paulo: Revista dos Tribunais, 2015.

NOGUEIRA, Pedro Henrique Pedrosa. Os limites linguístico-legislativos da discricionariedade judicial. Revista de Informação Legislativa, ano 46, n. ${ }^{\circ}$ 181, p. 320, jan./mar. 2009.

OLIVEIRA, José Roberto Pimenta. Os princípios da razoabilidade e da proporcionalidade do direito administrativo brasileiro. São Paulo: Malheiros, 2006.

PARKES, Tim. The Civil Procedure Rules tem years on: the practioners's perspective. In DWYER, Déirdre (ed.). The Civil Procedure Rules ten years on. Nova York: Oxford University Press, 2009.

PLATÃO. A República. Tradução Edson Bini. Bauru: Edipro, 2006.

PUOLI, José Carlos Baptista. O ônus da prova e sua distribuição dinâmica no novo Código de Processo Civil. In O novo Código de Processo Civil: questões controvertidas (vários autores). São Paulo: Atlas, 2015. 2002.

Os poderes do juiz e as reformas do processo civil. São Paulo: Juarez de Oliveira,

Processo e Constituição: alcance amplo, mas não ilimitado, dos princípios constitucionais do processo. In Direito Processual Constitucional. José Carlos Baptista Puoli, 
Marcelo José Magalhães Bonizzi, Ricardo de Barros Leonel (coords). Brasília: Gazeta Jurídica, 2016.

RODRIGUES, Marcelo Abelha. O novo CPC e a tutela jurisdicional executiva (parte 1). Revista de Processo, vol. 244, ano 40, p. 105, junho/2015.

SANTOS, Boaventura de Sousa. Para uma revolução democrática da justiça. Coimbra: Almedina, 2015.

SANTOS, Moacyr Amaral. Primeiras linhas de direito processual civil. São Paulo: Saraiva, 2002. Vol. 1.

SAUSSURE, Ferdinand de. Curso de linguística geral. Tradução Antônio Chelini, José Paulo Paes e Izidoro Blikstein. São Paulo: Cultrix, 2004.

SCARPINELLA BUENO, Cassio. Curso sistematizado de direito processual civil. São Paulo: Saraiva, 2008, vol. I.

SICA, Heitor. Preclusão processual civil. São Paulo: Atlas, 2008.

SILVA, José Afonso da. Aplicabilidade das normas constitucionais. São Paulo: Malheiros, 2002.

SILVA, Virgílio Afonso. A constitucionalização do direito - Os direitos fundamentais nas relações entre particulares. São Paulo: Malheiros, 2014.

SILVEIRA, Susana Amaral. Acordos incentivados - uma contribuição britânica nos caminhos buscados pelo Judiciário brasileiro. Tese de Doutorado. Faculdade de Direito da Universidade de São Paulo, 2010.

SORABJI, John. English civil justice: another attempt at a new approach to justice. Revista de Processo, vol. 243, ano 40, p. 94, mai/2015.

STRECK, Lenio et al. A cooperação processual do novo CPC é incompatível com a Constituição. Disponível em: <http://www.conjur.com.br/2014-dez-23/cooperacaoprocessual-cpc-incompativel-constituicao>._Acesso em 27.12.2017.

SUNDFELD, Carlos Ari. Direito Administrativo para céticos. São Paulo: Malheiros, 2014.

TARUFFO, Michele. A motivação da sentença civil. Tradução Daniel Mitidiero, Rafael Abreu, Vitor de Paula Ramos. São Paulo: Marcial Pons, 2015.

Pons, 2013.

Processo civil comparado: ensaios. Tradução Daniel Mitidiero. São Paulo: Marcial

TAVARES, João Paulo Lordelo Guimarães. Da admissibilidade dos negócios jurídicos processuais no novo Código de Processo Civil: aspectos teóricos e práticos. In Revista de Processo, São Paulo: Revista dos Tribunais, n. 254, ano 41, p. 106-107, abr/2016.

THEODORO JR, Humberto et al. Novo CPC - Fundamentos e sistematização. Rio de Janeiro: Forense, 2015. 
VELLOSO, Adolfo Alvarado. El garantismo procesal. Disponível em $<$ http://www.cartapacio.edu.ar/ojs/index.php/ctp/article/viewFile/19/54>. Acesso em 16.06.2017.

WAMBIER, Teresa Arruda Alvim. Existe a 'discricionariedade' judicial?. Revista de Processo, São Paulo: Revista dos Tribunais, vol. 70, ano 18, p. 232, abr./jul. 1993.

YARSHELL, Flávio Luiz. Antecipação da prova sem o requisito da urgência. São Paulo: Malheiros, 2009.

Convenção das partes em matéria processual: rumo a uma nova era? In Negócios processuais. Antonio do Passo Cabral, Pedro Henrique Nogueira (coords). Salvador: JusPodivm, 2005.

ZANDER, Michael. The Woolf Reforms: What's the verdict? In DWYER, Déirdre (ed.). The civil procedure rules ten years on. Nova York: Oxford University Press, 2009.

ZANETI JR., Hermes; PEREIRA, Carlos. Por que o Poder Judiciário não legisla no modelo de precedentes do Código de Processo Civil de 2015?. Revista de Processo, São Paulo: Revista dos Tribunais, vol. 257, ano 41, jul/2016. 